Primljen / Received: 14.10.2015. Ispravljen / Corrected: 24.5.2016.

Prihvaćen / Accepted: 12.9.2016. Dostupno online / Available online: 10.8.2017.

\section{Reliability assessment of water distribution network using informational entropy considering design/hydraulic parameters}

Authors:

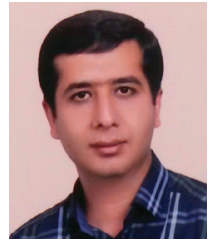

Mostafa Ghanbari Kashani, MCE

Islamic Azad University

Department of Civil Engineering

Science and Research Branch

Teheran, Iran

mostafa.gh.k@gmail.com

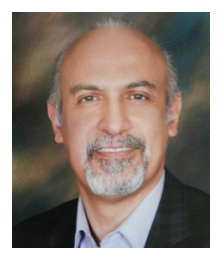

Assoc.Prof. Mahmood Hosseini, PhD. CE International Institute

of Earthquake Engineering and Seismology Teheran, Iran

mahmood.hosseini@gmail.com

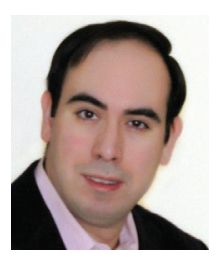

Assist.Prof. Armin Aziminejad, PhD. CE Islamic Azad University

Department of Civil Engineering

Science and Research Branch

Teheran, Iran

armin.aziminejad@gmail.com
Preliminary note

Mostafa Ghanbari Kashani, Mahmood Hosseini, Armin Aziminejad

Reliability assessment of water distribution network by means of informational entropy using design/hydraulic parameters

A modified entropy-based criterion for evaluating reliability of water distribution networks is presented in the paper. Design and hydraulic parameters, as well as failure probabilities for individual links, are considered. For this purpose, a new weighting factor is defined based on the proportion of total outflow at each node to the total network dissipated power. Another weighting factor is defined based on the relation between the flow rate of a link and the total flow rates in the network, to take into account the capacity of individual links, as compared to that of the overall network.

Key words:

water distribution network, reliability assessment, desigm and hydraulic parameters, informational entropy

Prethodno priopćenje

Mostafa Ghanbari Kashani, Mahmood Hosseini, Armin Aziminejad

Ocjena pouzdanosti vodoopskrbne mreže pomoću informacijske entropije primjenom projektnih/hidrauličkih parametara

U radu se prikazuje primjena kriterija temeljenog na svojstvu entropije za ocjenjivanje pouzdanosti vodoopskrbne mreže. Pri tome se u obzir uzimaju projektni i hidraulički parametri te vjerojatnost potpunog ispada iz rada (otkazivanja) cjevovoda. Na temelju odnosa ukupnog izlaznog protoka iz pojedinog čvora i ukupnog gubitka snage, u čitavoj mreži definiran je novi ponderski faktor. Definiran je i dodatni ponderski faktor koji se temelji na odnosu protoka u pojedinoj dionici i ukupnom protoku u mreži, pri čemu se u obzir uzima protočni kapacitet pojedine dionice u odnosu na cjelokupnu mrežu.

Ključne riječi:

vodoopskrbna mreža, ocjena pouzdanosti, projektni i hidraulični parametri, informacijska entropija

Vorherige Mitteilung

Mostafa Ghanbari Kashani, Mahmood Hosseini, Armin Aziminejad

Bewertung der Zuverlässigkeit des Wasserversorgungsnetzes mit Hilfe der Informationsentropie, durch die Anwendung der Projektparameter/der hydraulischen Parameter

In der Arbeit wird die Anwendung der Kriterien angewendet, die sich auf der Eigenschaft der Entropie gründen, und zwar für die Bewertung der Zuverlässigkeit des Wasserversorgungsnetzes. Dabei werden die Projekt- und Hydraulikparameter, sowie die Wahrscheinlichkeit des vollkommenen Betriebsausfalls (Ausfall) der Rohrleitung. Aufgrund des Verhältnisses des gesamten Ausgangsdurchflusses aus dem einzelnen Knoten, sowie aufgrund des gesamten Kraftverlustes wurde im gesamten Netz der neue Ponderfaktor definiert. Es wurde auch der zusätzliche Ponderfaktor definiert, welcher sich auf dem Verhältnis des Durchflusses in der einzelnen Strecke, sowie auf dem gesamten Durchfluss im Netz gründet, wobei die Durchflusskapazität der einzelnen Strecke im Verhältnis zum gesamten Netz berücksichtigt wird.

Schlüsselwörter:

Wasserversorgungsnetz, Bewertung der Zuverlässigkeit, Projekteigenschaften und hydraulische Eigenschaften, Informationsentropie 


\section{Introduction}

Water distribution networks are usually designed to perform two main roles: a) supplying water at sufficient pressure and quantity to consumers, and b) providing adequate water for firefighting purposes.

Over the past few decades, research on water distribution networks has mainly been focused on network reliability issues, leading to introduction of several reliability criteria [1-6].

Reliability of a water distribution network can be defined as the probability that any given demand node in the system will receive sufficient supply with satisfactory pressure head [7]. It has been calculated through different methods in the literature. To the best of the available knowledge, network reliability could be calculated via two types of methods, namely, exact methods, which require considerable amount of calculations, and approximate methods, which are less time consuming but produce a lot of errors in some cases. Accordingly these two methods resultinexactand approximate reliability indices, respectively [8]. Due to the disadvantages of each of the exact and approximate methods, several researchers have suggested using informational entropy for assessing reliability of water distribution networks. In fact, they have pointed out that the entropy amount could be used as a general performance indicator for assessing reliability of water distribution systems [9]. In this case, several advantages over other performance and reliability indices should be noted. For example, these methods are extremely rapid and much easier in terms of calculation compared to other measures. They do not require many data and can be directly incorporated into design optimization frameworks [10]. In addition, they could be considered a measure of system redundancy [11].

Redundancy in a water distribution network implies the reserve capacity of the network, and that the demand nodes have alternative supply paths in case links fail to provide the desired service [11]. Redundancy, which is closely related to reliability, is an aspect of the overall system performance that is often neglected. A true redundant network is inherently very reliable. Seismic performance of lifeline networks during past earthquakes has revealed that a single redundancy increases the reliability dramatically. In other words, networks with some amount of redundancy are more effiAcient in responding to partial failures in the network [12]. Javanbarg and his colleagues [12] have mentioned that redundancy and reliability of a water distribution system can be investigated from two points of view, namely, the hydraulic perspective and seismic risk assessment. From the hydraulic point of view, the redundancy and reliability have been extensively studied by Awumah and his colleagues [11], and by Kalungi and Tanyimboh [13]. In case of seismically damaged networks, Hoshiya and Yamamoto [14], and Hoshiya and his colleagues [12], proposed a redundancy index with regard to the entropy of an event of damage modes conditioned on system damage.

Awumahand hiscolleagues $[9,11]$ seem to betheearliestresearchers to propose the use of the Shannon's entropy function [16] as a surrogate measure for assessing reliability of water distribution networks. Later, by using a multiple probability space model and the conditional probability of Khinchin [17], Tanyimboh and Templeman
[18] proposed a more suitable definition of the entropy function for water distribution networks. Tanyimboh and Templeman [19] also developed a non-iterative algorithm to find the maximum-entropy flow distribution for single-source networks. In their study, the known data were assumed to be the network topology, the flow directions in every link, and the amount of supply and demand at every node, whereas parameters such as the link length, diameter, and roughness were not considered in entropy calculations. They also tried to extend the single source algorithm to cover multiplesource networks by using the super-source concept. However, this extended version of the single-source algorithm for multiple-source networks was proven to be inappropriate in a paper by Walters [20]. In another study, Yassin-Kassab and his colleagues [21] presented a non-iterative algorithm based on the single-source algorithm for calculating the maximum entropy flow distribution in multiple source networks. Later, the relationship between the entropy and reliability of water distribution networks was investigated by Tanyimboh and Templeman [22] whose study supports the hypothesis that water distribution networks designed to carry the maximum entropy flows are more reliable.

Ang and Jowitt [23] investigated the meaning of network entropy by using a simple water distribution network. Their research explored the relationship between the total power dissipated by the water distribution network and the numerical value of the network's entropy. In two other articles [24, 25], they presented an alternative method to calculate the network entropy of water distribution systems, which has resulted in new insights into the concept of network entropy. Their alternative method, termed the Path Entropy Method (PEM), offers a simpler explanation of the entropy of branching-tree networks and the maximum entropy of water distribution networks. The formulation of the PEM was based on the different paths available to a water molecule for moving from a super-source to a super-sink.

In their definition of entropy function, Tanyimboh and Templeman failed to take into account the differences between branchingtree networks having different layouts and the same number of supply and demand nodes which all have the same PEM diagram. To overcome this problem, and to take into account the effect of both design and hydraulic parameters of the network in entropy calculations, Hosseini and Emamjomeh [26] introduced a penalty value for each link, which is equal to the amount of water loss in that link in case of its failure, based on which a new weighting factor was suggested. The order of the demand nodes in the network was considered in entropy calculations by introducing a new coefficient in the entropy function. In order to take into account the simultaneous effects of design and hydraulic network parameters Hosseini and Emamjomeh considered the breakage probability of the links by introducing a penalty function for each link of the network in any hazard scenario. Then, this penalty function was inserted satisfactorily in the original entropy function of the network. Nevertheless, the method proposed by Hosseini and Emamjomeh suffers from a disadvantage of losing the precision in some cases as described in the following sections of the paper.

Having a more profound look at the previous definitions of water distribution networks entropy, reviewed above, it is clear that those 
definitions and related calculations do have some shortcomings, such as discarding the hydraulic features of the network in combination with its design parameters, and losing the precision in entropy calculations with consideration of links' failure probabilities. The aim of this study is to present a modified entropy function for assessing reliability of water distribution networks while considering failure probability of links and both design and hydraulic parameters of the system, in which there is no loss of precision in entropy calculations. In the following section of this paper, preliminary definitions for entropy function and its deficiencies are initially discussed, and then a modification for incorporating the effects of both design and hydraulic parameters of the network in the entropy function is proposed. After that, another modification for incorporating links' failure probability in entropy function calculations is suggested and, finally, the authors propose a modified entropy function calculation applied to some sample networks of various parallel, series, and loop types, as well as a part of the Kobe city water distribution network to show its efficiency.

\section{Entropy function for water distribution networks and its previous modifications}

The formulation of the entropy function mainly relies on the Shannon's measure of uncertainty [16], which is an underlying principle of information theory. Tanyimboh and Templeman [18] were the first to develop an entropy function by using the multiple probability space models and the Khinchin's conditional probability [17]. The available network data are the topological layout, the amount of supply and demand at all nodes, and the flow direction in each link. It is noteworthy that the flow direction in each link is a key assumption as there will be a maximum entropy flow distribution for each set of flow directions. The network entropy function developed by Tanyimboh and Templeman is as follows:

$\frac{S}{K}=S=S_{o}+\sum_{n=1}^{N} P_{n} S_{n}$

where $S$ is the entropy defined by Shannon, $N$ is the total number of nodes, and $K$ is the Boltzman constant which is usually set to unity. The entropy of the external inflows, $S_{0}$, is represented by:

$S_{0}=-\sum_{i \in l} P_{0 i} \ln P_{0 i}$

where / is the set of all source nodes, and

$P_{0 i}=\frac{q_{0 i}}{T_{0}}$

where $q_{0 i}$ is the external inflow at source node $i$, and $T_{0}$ is the total supply or demand of the network. The second term in the entropy function, expressed by Eq. (1), consists of the outflow entropy at each node, $S_{n^{\prime}}$ weighted by the $P_{n}$ ratio, which is equal to the ratio of the total outflow of each node to the total inflow of the whole network, i.e.:

$P_{n}=\frac{T_{n}}{T_{0}}$

where $T_{n}$ is the total outflow at node $n$. An important point in the definition of outflow is that it is inclusive of any demand at the node. In Eq. (1), the outflow entropy at each node, $S_{n^{\prime}}$ is given by:

$S_{n}=-\sum_{n j \in N D_{n}} P_{n j} / n P_{n j}$

where $N D_{n}$ is the set of all outflows from node $n$, and

$P_{n j}=\frac{q_{n j}}{T_{n}}$

where $q_{n j}$ is the flow from node $n$ to node $j$. Entropy function in Eq. (1) shows that the entropy of a water distribution network has two components. The entropy of the external inflows, $S_{0}$, as the first component, is the uncertainty faced by a water molecule moving from the super-source to the individual supply nodes. This term is non-zero for multiple-source networks and zero for single-source networks. Moreover, the second part consists of the weighted entropy values at every demand node. It should be noted, as shown in the formulae presented above, that the length, diameter, and roughness of the network's links are not used directly in the Tanyimboh-\&-Templeman's formulation. Furthermore, their formulation does not consider the effects of connectivity state and order of the network's nodes to the source node, while these factors particularly determine functional sensitivity of a network. To add these effects in entropy function, Hosseini and Emamjomeh [26] defined a penalty value $T_{p}$ for each link, which is equal to the amount of loss in case of its failure. Based on these penalty values, they introduced a new weighting factor $P_{n}$ as follows:

$P_{n}^{\prime}=\frac{T_{n}}{T_{P}}$

where $T_{p}$ is the summation of penalty values for all links in the network. They used this weighting factor instead of the previous one, $P_{n}$ in Eq. (1), in the calculation of networks' entropy values, while the rest of the calculations were the same as the Tanyimboh-\&-Templeman's calculations. To gain a better insight into Tanyimboh-\&-Templeman's entropy function, a simple fullyconnected water distribution network, as shown in Figure 1 [26], has been considered, and its entropy has been calculated. This network has one source and three demand nodes, and its entropy value amounts to 1.9073, as shown in the Figure 1.

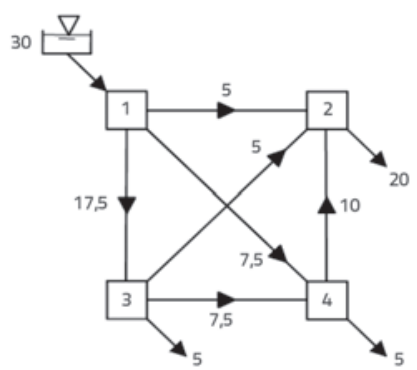

$\begin{aligned} S= & -\frac{30}{30} \cdot\left[\frac{5}{30} \ln \left(\frac{5}{30}\right)+\frac{17,5}{30} \ln \left(\frac{17,5}{30}\right)+\frac{7,5}{30} \ln \left(\frac{7,5}{30}\right)\right] \\ & -\frac{17,5}{30} \cdot\left[2 \cdot \frac{5}{17,5} \ln \left(\frac{5}{17,5}\right)+\frac{7,5}{17,5} \ln \left(\frac{7,5}{17,5}\right)\right]-\frac{15}{30} \cdot\left[\frac{5}{15} \ln \left(\frac{5}{15}\right)+\frac{10}{15} \ln \left(\frac{10}{15}\right)\right]=1,9073\end{aligned}$

Figure 1. Fully-connected network sample with maximum network entropy and details of its entropy calculations [26] 


\section{Deficiencies of previous definitions of entropy function}

To show deficiencies of the Tanyimboh-\&-Templeman's entropy function and its modified function proposed by Hosseini and Emamjomeh [26], a simple loop network was considered with three different possible flow directions, used by Ang and Jowitt [23], as shown in Figure 2.

According to Figure 2, it can easily be understood, by paying attention to the key role of link 1-2 in supplying the node with highest demand, that the reliability of network in state (a) is greater than that of state (b), and the reliability of network in state (b) is greater than that of state (c). In fact, breakage of link 1-2 in states (a), (b), and (c) causes the water loss of 10 , 22.5 , and $27.5 \mathrm{~L} / \mathrm{s}$, respectively. Furthermore, the maximum difference between the flow rates in the network's links in state (a) is $10 \mathrm{~L} / \mathrm{s}$, while this difference is $20 \mathrm{~L} / \mathrm{s}$ and $25 \mathrm{~L} / \mathrm{s}$ in states (b) and (c), respectively. Based on these two facts it is expected that the network in state (a) has a greater entropy value than state (b), and that entropy is greater in state (b) compared to state (c). This is why, as shown in Figure 2, neither Tanyimboh\&-Templeman's function, nor the modified function proposed by Hosseini and Emamjomeh result in values compatible with the above facts. Particularly, the modified function proposed by Hosseini and Emamjomeh gives a smaller value for the state (a), which is quite contrary to expectations. The reason behind this unexpected result is the way they have defined the penaltybased weighting factor for each node of the network in which, as shown in Eq. (7), the parameter $T_{p}$ (the summation of flow rate of all links in the network, which is generally larger than the total supply of the network) appears in denominator, and therefore, has a decreasing effect on the value of all weighting factors used in the calculation of entropy. On this basis, Hosseini and Emamjomeh's modified entropy function cannot determine the exact difference between the reliability of different networks with the same design parameters such as length, diameter, and roughness coefficient.

To overcome the abovementioned deficiencies, a modification is proposed in the next section based on a new weighting factor in the entropy function, and is applied to a sample network to show its efficiency.

\section{Incorporating the effects of design parameters of the network in the entropy function}

The modification proposed in this paper for overcoming the mentioned deficiencies in calculation of the network entropy is based on the dissipated power by which, in addition to the hydraulic parameters of the network as its main feature for entropy calculation, the design parameters of the network such as length, diameter, and roughness of the links are also taken into account. For this purpose, a new weighting factor $P_{n^{\prime}}^{\prime \prime}$ based on the amount of the dissipated power calculated in each link, is defined for each node of the network, as follows:

$P_{n}^{\prime \prime}=\frac{T_{n}}{\sum_{i=1}^{n !} P_{w i}}$

where, similarly to the function proposed by Tanyimboh- $\&$ Templeman, $T_{n}$ is the total outflow at node $n, \sum_{i=1}^{n l} P_{w i}$ is the total dissipated power by the water distribution network, and $n /$ is the total number of the links in the network. The dissipated power by link $i, P_{w i}$ can be calculated as:

$P_{w 1}=\rho g h_{i} Q_{i}$

where $\rho$ is the water density, $g$ is the gravity acceleration, $h_{i}$ is the head loss for link $i$, and $Q_{i}$ is the flow rate of link $i$. In this study, the link friction head loss is computed using the HazenWilliams equation:

$h_{i}=\frac{10.6 L_{i}}{D_{i}^{4.865} C_{i}^{1.85}} Q_{i}^{1.85}=k_{i} Q_{i}^{1.85}$

where

$L_{i}$ - the length of the link $i[\mathrm{~m}]$

$D_{i}$ - the diameter of link $i[\mathrm{~m}]$

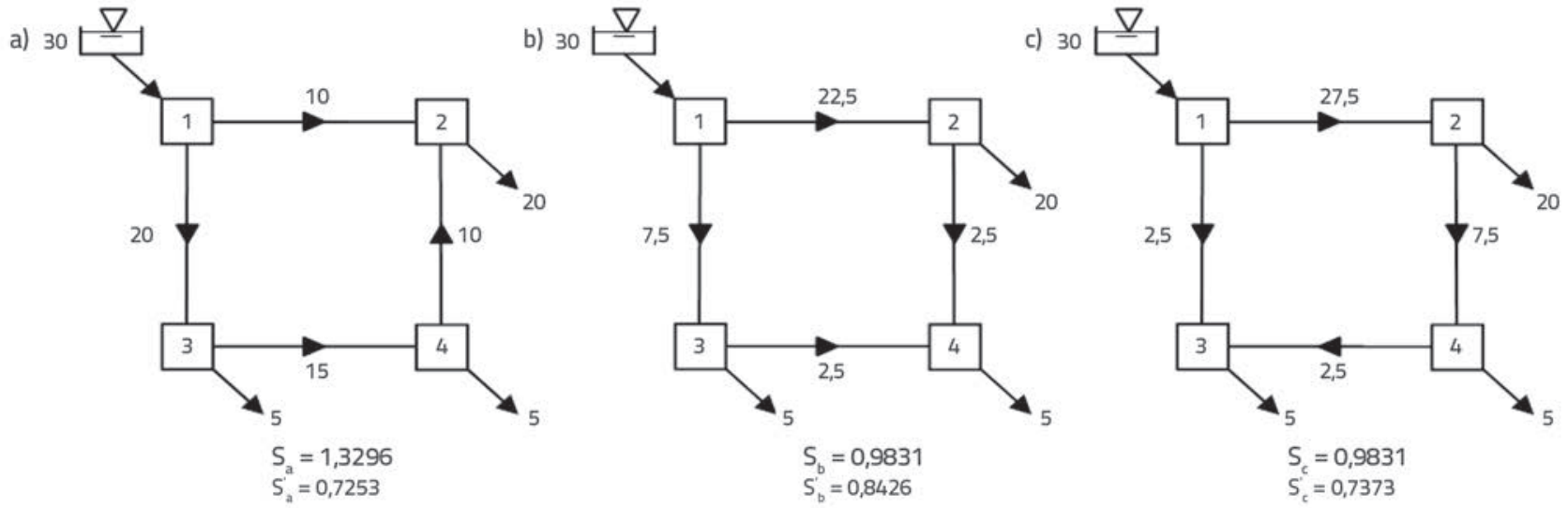

Figure 2. Simple loop network with three different possible flow directions and associated entropy amounts using Tanyimboh- $\&$-Templeman's function (S) and the modified function proposed by Hosseini and Emamjomeh ( $\mathrm{S}^{\prime}$ ) 
$C_{i}$ - the roughness coefficient of link $i$

$k_{\mathrm{i}} \quad$ - the resistance coefficient of link $i\left[\mathrm{~s} / \mathrm{m}^{2}\right]$.

Based on the equations (9) and (10) the dissipated power by link ican be calculated as:

$P_{w 1}=\rho g k_{i} Q_{i}^{2.85}$

In Eq. (11) the coefficient $k_{i}$ is:

$k_{i}=\frac{10.6 L_{i}}{D_{i}^{4.865} C_{i}^{1.85}}$

Regarding that $Q_{i}=A_{i} \times v_{i}=\left(\pi \times D_{i}^{\wedge} 2 / 4\right) \times v_{i} \quad\left(v_{i}\right.$ being the current velocity in the pipe), and assuming an average constant value for $v_{i}$ one can write:

$D_{i}=\alpha \sqrt{Q_{i}}$

Substituting $Q_{i}$ in Eq. (11) results in:

$P_{w l}=\rho g \theta Q_{i}^{0.4175}$

where:

$\theta=\frac{10.6 L_{i}}{\alpha^{4.865} C_{i}^{1.85}}$

Having the values of $P_{w w^{\prime}}$ obtained by Eq. (14), each one being a function of its corresponding $Q_{i}$ value, the values of $P^{\prime \prime}$ are calculated by Eq. (8), and are used instead of $P_{n}$ in Eq. (1) for calculating the network entropy, while the rest of the calculations are the same as before.

To show the effect of the proposed modification, the entropy values for the three states of the sample network shown in Figure 2, are calculated by Tanyimboh-\&-Templeman's function (S), the modified entropy function suggested by Hosseini and Emamjomeh $\left(\mathrm{S}^{\prime}\right)$, and the proposed entropy function in this study ( $\left.\mathrm{S}^{\prime \prime}\right)$, by assuming the length, diameter, and roughness coefficient of all links to be $890 \mathrm{~m}$, and 130, respectively, based on the study conducted by Ang and Jowitt [23]. For example, the entropy value for the network in state (a), by using the modified entropy function, is calculated as follows:

$P_{w(1-2)}=P_{w(4-2)}=2453.94 W, P_{w(1-3)}=3277.50 W, P_{w(3-4)}=2453.94 W$

$\sum_{i=1}^{4} P_{w i}=11091.95 W$

$S_{a}^{\prime \prime}=-\frac{30}{11091.95} \times\left[\frac{10}{30} \ln \left(\frac{10}{30}\right)+\frac{20}{30} \ln \left(\frac{20}{30}\right)\right]-\frac{20}{11091.95} \times\left[\frac{5}{20} \ln \left(\frac{5}{20}\right)+\frac{15}{20} \ln \left(\frac{15}{20}\right)\right]$ $-\frac{15}{11091.95} \times\left[\frac{5}{15} \ln \left(\frac{5}{15}\right)+\frac{10}{15} \ln \left(\frac{10}{15}\right)\right]=0.0036$
Complete results of the entropy calculations by the three mentioned methods are presented in Table 1.

According to Table 1, the entropy values calculated by the modified entropy function are quite compatible with expectations for the three considered network states. As can be seen, the entropy value of the network is more in state (a) than state (b) and more in state (b) than state (c).

Table 1. Entropy values of the sample network calculated by three discussed methods

\begin{tabular}{|c|c|c|c|}
\hline \multirow{2}{*}{ Discussed methods } & \multicolumn{3}{|c|}{ The network states } \\
\cline { 2 - 4 } & $\mathbf{a}$ & $\mathbf{b}$ & $\mathbf{c}$ \\
\hline $\boldsymbol{S}$ & 1,3296 & 0,9831 & 0,9831 \\
\hline $\begin{array}{c}\boldsymbol{S}^{\prime} \\
\text { (Tanyimboh\&Templeman) }\end{array}$ & 0,7253 & 0,8426 & 0,7373 \\
\hline $\begin{array}{c}\boldsymbol{S}^{\prime \prime} \\
\text { (Authors of this paper) }\end{array}$ & 0,0036 & 0,00352 & 0,0034 \\
\hline
\end{tabular}

\section{Incorporating failure probability in entropy function}

In the previous section, the dissipated power in the network is used to propose a new weighting factor to incorporate the design parameters such as length, diameter, and roughness of links in the entropy function, and, in turn, specify the difference between the reliability of various design parameters of the network. However, in case of a network subjected to earthquake, each component of the network is susceptible to damage. In order to consider the probability of links' failure in network entropy function, Hosseini and Emamjomeh [26] defined a penalty function based on the probability of failure of each link, making it completely out of service, and incorporated it in the entropy function. On this basis, they presented a modified version of the outflow entropy at each node as follows:

$S_{n}=-\sum_{n j \in N D_{n}} P_{n j} \ln \left(\frac{P_{n j}}{1-P f_{n j}}\right)$

where $P_{n j}$ is calculated in the same way, as proposed by Tanyimboh and Templeman, and $\mathrm{Pf}_{n j}$ is the failure probability of the link between the node $n$ and node $j$, which can be obtained by using the analytical failure estimation of a specified scenario or using expert judgment. By using the above definition for $S_{n^{\prime}}$ the total modified entropy of the network, with inclusion of links' failure probabilities can be calculated as follows:

$\frac{S}{K}=S=S_{0}+\sum_{n=1}^{N} P_{n}^{\prime} S_{n}-\ln (\varepsilon)$

where the term $-\ln (\varepsilon)$ is added to avoid producing any negative entropy values, $\varepsilon$ being a small value between zero and one such as 0.01 [26]. In fact, in the Hosseini and Emamjomeh's function, 
considering the value of 1.0 for failure probability is not possible because the denominator of the term in parentheses would be zero, making the term mathematically meaningless. Therefore, they have assumed that the failure probability of a completely damaged link is equal to $1-\varepsilon$ instead of 1.0 .

It should be noted that the term $-\ln (\varepsilon)$ in entropy function generates errors when it is utilized as a comparative criterion for evaluating a network's reliability. For example, in the network shown in Figure 1, if the failure probability of all links is zero, and only the failure probability of link 1-3 equals 0.5 , the network entropy calculated by Hosseini and Emamjomeh's function (Eq. (17)) would be 5.464 and 0.859, depending on whether the term $-\ln (\varepsilon)$ is considered or not. If link 1-3 in this network is replaced by another link so that the failure probability of that link would equal zero, the network entropy with and without considering the term $-\ln (\varepsilon)$ would be 5.695 and 1.09, respectively. Consequently, the network performance would improve by $4 \%$ and $27 \%$, depending on whether term $-\ln (\varepsilon)$ is considered or not. In this study, for calculating the entropy value by inclusion of links' failure probabilities, the term $\left(1-\mathrm{Pf}_{n j}\right)$ is incorporated in $S_{n}$ as follows:

$S_{n}=-\sum_{n j \in N D_{n}}\left(1-P f_{n j}\right) P_{n j} \ln \left(P_{n j}\right)$

By using this equation, when the failure probability of a link is $100 \%$, its corresponding term in the entropy function vanishes, as expected. However, by a deeper insight into mathematical terms in the entropy function, it can be seen that the value of $P_{n j} \ln \left(P_{n j}\right)$ term for links with higher flow rates is less than those with lower flow rates. But, if the entropy is considered as a reliability criterion, it is expected that a link with higher flow rate exerts a greater influence on the entropy value of the whole network. In other words, elimination of a link with a higher flow rate reduces the reliability significantly. For example, in the network shown in Figure 1, the term related to link 1-3, $(17.5 / 30) * \ln (17.5 / 30)$, equals -0.3144 , while the term related to link $1-4,(7.5 / 30)^{*} \ln (7.5 / 30)$, is -0.3460 . This means that contrary to what is expected, a link with a higher flow rate and higher importance, in comparison with a link with a lower flow rate and lower importance, exerts a lower influence on the entropy value of the whole network. To eradicate this illogical outcome, a weighting factor can be defined for each link of the network as follows:

$w I_{n j}=\frac{q_{n j}}{\sum_{i=1}^{n l} q_{i}}$

where $q_{n j}$ is the flow rate of the link, from node $n$ to node $j$, and $\sum_{i=1}^{n} q_{i}$ is the total flow rate of the network links. Incorporating this factor into Eq. (14) gives it modified versions as follows:

$S_{n}=-\sum_{n j \in N D_{n}}\left(1-P f_{n j}\right) w l_{n j}\left(P_{n j} \ln P_{n j}\right)$

It is worth mentioning that, similar to previous studies, in this study the failure means full breakage, i.e. the complete out of service situation. The cases in which failure means a wide range of damage, from slight leakage to full breakage is beyond the scope of this study, and will hopefully be addressed in a future work. Regarding that the entropy value depends, to a great extent, on the network status, being parallel, series, loop, or complex. Applications of the proposed modified formula in entropy calculation of these states are discussed separately in the next section.

\section{Application of proposed entropy function in parallel networks}

A completely parallel network, already used by Hosseini and Emamjomeh [26] for assessment of their own proposed function, has been used In order to investigate the application of the proposed entropy function in parallel networks. The considered parallel network has one supply node, one demand node, and two parallel links in which failure probability of links are $\mathrm{Pf}_{1}$ and $\mathrm{Pf}_{2}$. In this network, a water molecule has only two choices, namely, $P_{1}=x$ and $P_{2}=1-x$, in which $x$ is the probability of selecting link 1 by a water molecule. Figure 3 shows this network and its Venn's diagram.

a)

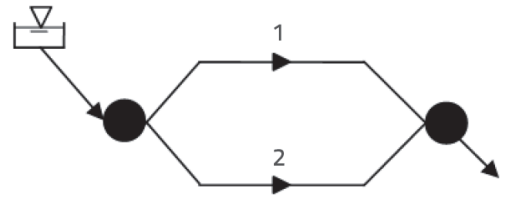

b)

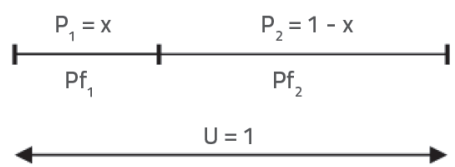

Figure 3. a) Two-link sample parallel network; b) its Venn's diagram [26]

The entropy value of the network shown in Figure 3a can be calculated for two states, i.e., when the failure probabilities of the two links are the same or they are different. Figure 4 shows the variation of the proposed entropy function (S") for different failure probabilities.

As can be seen in Figure 4a, when failure probabilities of the two links are the same, the maximum entropy occurs when the probabilities of choosing the two links, by a water molecule, are exactly the same. In other words, the maximum entropy value corresponds to $x=0.5$, and the graph of the entropy function is symmetric with respect to this value. However, when the failure probabilities of the two links are different, as in Figure 4b, the graph of the entropy function is asymmetric with respect to the centreline of the graph, as expected. In fact, according to Figure $4 b$, the entropy value is higher if the link with higher probability failure is less likely to be chosen, which is exactly in line with expectations. 

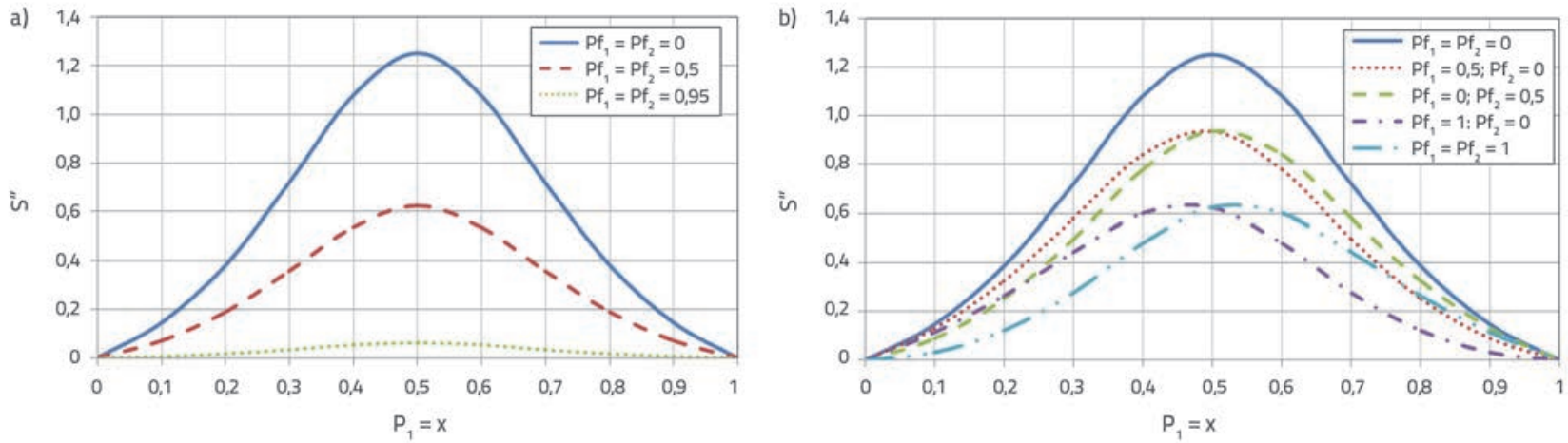

Figure 4. Variation of the proposed entropy function, with respect to the probability of selecting link 1 by a water molecule, for the sample parallel network having two links, in two states: a) the same failure probabilities for the links; b) different failure probabilities for the links

The decrease of the entropy values with an increase in the probability of link failure is also observed in Figure 4. Also, the symmetry of graphs corresponding to the counterpart states (for example $\mathrm{Pf}_{1}=0, \mathrm{Pf}_{2}=0.5$ and $\mathrm{Pf}_{1}=0.5, \mathrm{Pf}_{2}=0$ ), with respect to the centreline is seen in the Figure.

\section{Application of proposed entropy function in series networks}

In order to investigate the variation of the proposed entropy function in series networks, the same network utilized by Hosseini and Emamjomeh [26], which is a network with one supply node and two demand nodes, has been considered. These nodes are connected serially as shown in Figure 5.

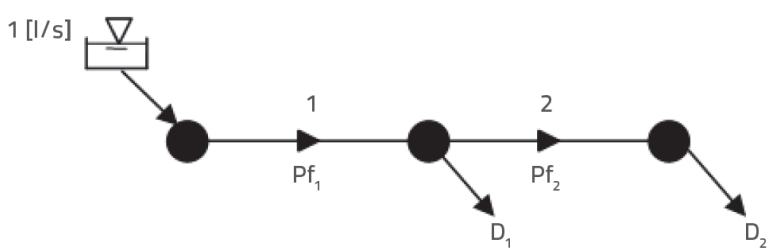

Figure 5. The sample series network with two connected links [26]

For calculating the network entropy value in each case, the term related to the failure probability of the first link, $1-\mathrm{Pf}_{1}$ is multiplied by the whole term of the first demand, resulting in the following equation.

$S^{\prime \prime}=S_{0}+\sum_{n=1}^{N} P_{n}^{\prime \prime} S_{n}=\frac{T_{n}}{\sum_{i=1}^{n l} P_{w i}}\left(1-P f_{1}\right) \sum_{n j \in N D_{n}}\left(1-P f_{n j}\right) w l_{n j}\left(P_{n j} / n P_{n j}\right)$

It is worth mentioning that in the conventional entropy calculation, link 1 of the network, shown in Figure 5, is not incorporated in the calculations, and accordingly, the effect of its failure probability cannot be taken into account in entropy calculation. On the other hand, by using the proposed modified formula, Eq. (21), the failure probability of all the network links is taken into account. Figure 6 shows the entropy variations in the considered series network for different failure probabilities of one or two links, with different demand ratios in its demand nodes, assuming $\rho g k_{i}$ to be equal to 1.0 in calculation of $P_{\text {wi }}$
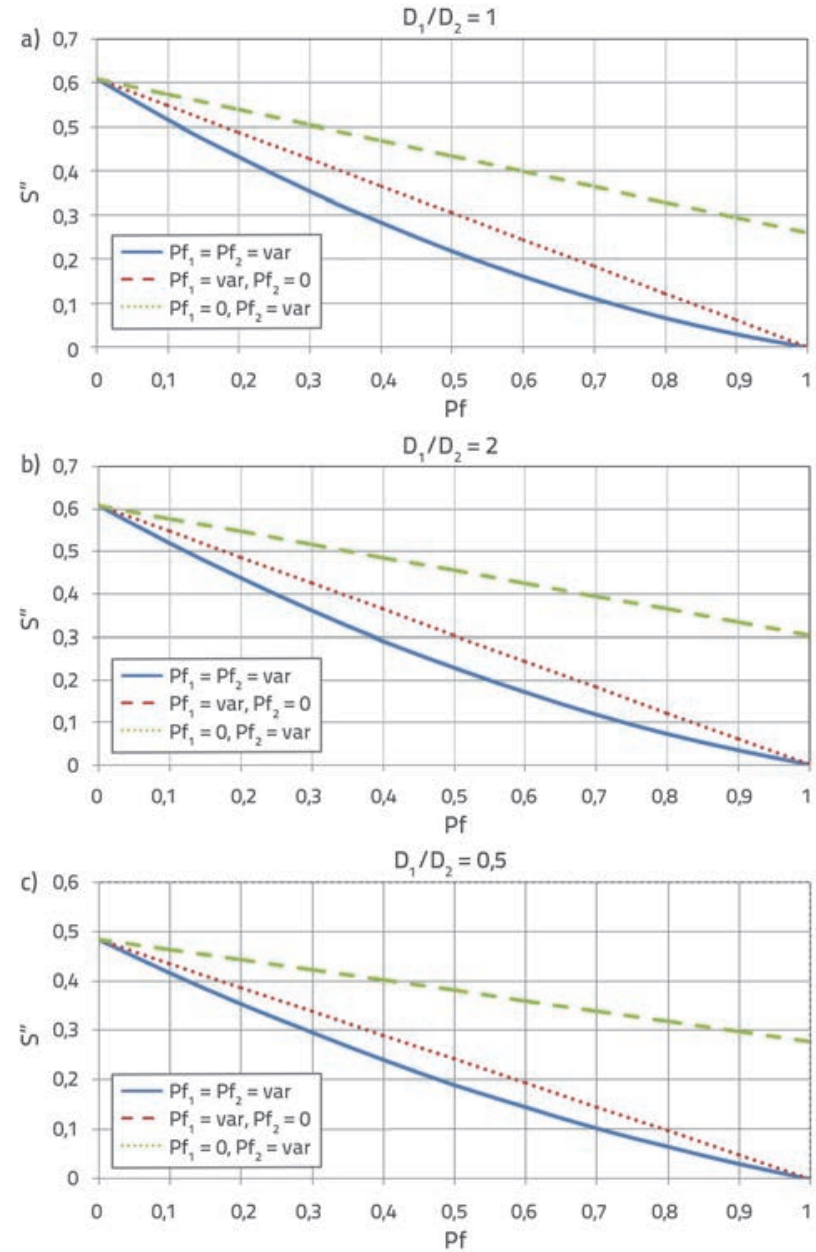

Figure 6. Entropy variation in sample series network with respect to failure probabilities of links 1 and 2 for three values of $D_{1}$ I $D_{2}$ ratio

As can be seen in Figure 6, the entropy value decreases with an increase in the link failure probabilities, as expected. 
Furthermore, the network entropy value is more sensitive to the failure probability of link 1, i.e. the one closer to the source. When the failure probability of link 2 is zero, the value of entropy is lower than when that of link 1 is zero. The second point to infer from the diagrams is that the proposed function takes into account the connectivity order of demand nodes to the supply node. As can be seen in case of $D_{1} / D_{2}=2$, (Figure $6 b$ ), i.e. when the node with greater demand is closer to the source, the entropy value is higher than in the case of $D_{1} / D_{2}=2=0.5$, (Figure 6c), where the node with higher demand is farther from the source.

\section{Application of the proposed entropy function in loop networks}

A network with one supply node and three demand nodes, shown in Figure 7, used by Hosseini and Emamjomeh [26], was considered to assess the proposed entropy function in loop networks.

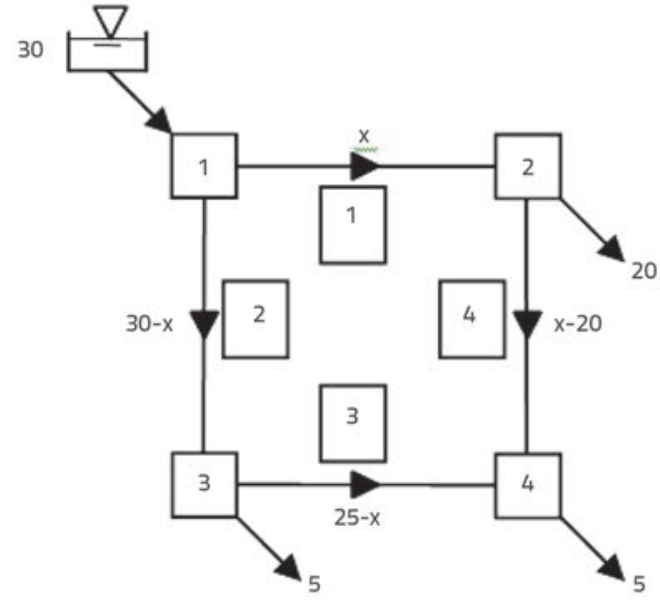

Figure 7. Sample water distribution loop network with one source node and three demand nodes [26]

Assuming that there is no limitation in terms of the flow rate and flow direction in the network's links, all possible network patterns could be taken into account. There are a total of three different states of flow directions for topological layouts of the network as shown in Figure 8.

For a given set of demands, if the flow rate of link 1 (in Figure 7) is taken as $x$, the flow rate in the remaining links could easily be determined from the flow equilibrium at each node, which is shown in Figure 7. Considering the total demands of different nodes and all possible flow directions, the resulting flow rates for each link are as shown in Table 2, where negative values are related to the cases in which flow directions are opposite to the ones shown in Figure 7.

Table 2. Possible flow rates for loop network links shown in Figure 7

\begin{tabular}{|c|c|c|c|}
\hline Link number & Start node & End node & Flow rate (Q) \\
\hline 1 & 1 & 2 & $0 \leq x \leq 30$ \\
\hline 2 & 1 & 3 & $0 \leq 30-x \leq 30$ \\
\hline 3 & 3 & 4 & $-5 \leq 25-x \leq 25$ \\
\hline 4 & 2 & 4 & $-20 \leq x-20 \leq 10$ \\
\hline
\end{tabular}

Based on the entropy function proposed by Tanyimboh and Templeman (Eq. (1)), entropy variation of the loop network versus the flow rate of link 1, namely $x$, is shown in Figure 9 [26].

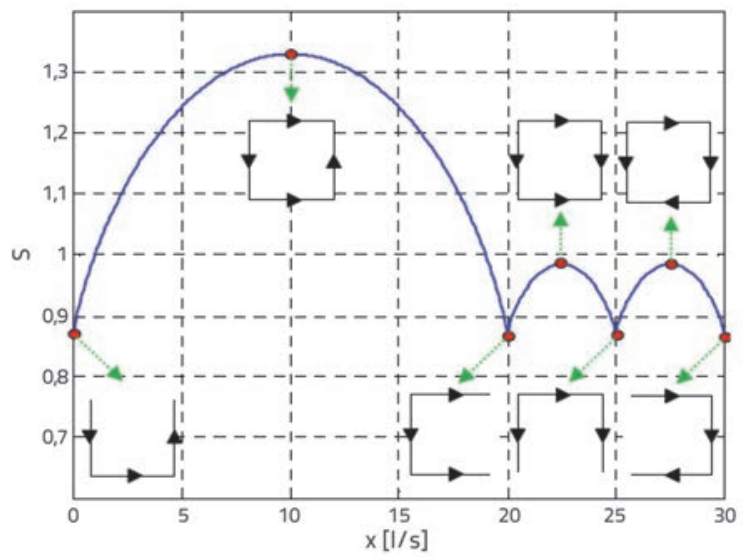

Figure 9. Entropy variations of sample loop network shown in Figure 9 versus flow rate $x$ in link 1, based on entropy function proposed by Tanyimboh and Templeman [26]

As Hosseini and Emamjomeh [26] mentioned, based on Tanyimboh-\&-Templeman's formula, the graph has four similar minimal values, each belonging to one of the branching-tree sub-systems, shown below the graph. Also there are three relative maximal values each one belonging to one of the specific flow direction patterns shown in Figure 8. With a deeper insight into the loop network, shown in Figure 7, one can realize that by assigning some specific values to $x$, four different branching-tree networks can be formed, as shown in Figure 10, where entropy values calculated by the three methods under discussion ( $S, S^{\prime}$ and $\left.\mathrm{S}^{\prime \prime}\right)$ are also given.

Figure 8. Possible states of flow direction in sample loop network links

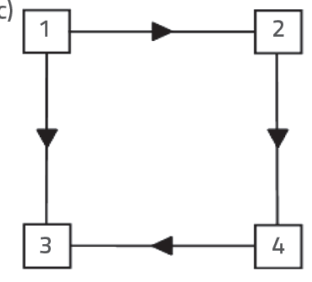




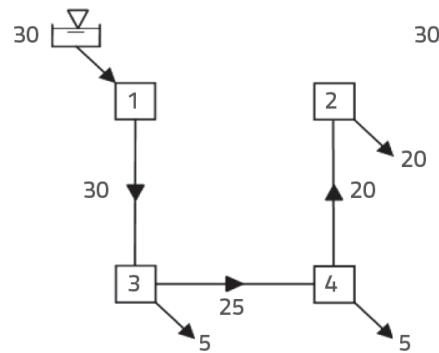

(1)

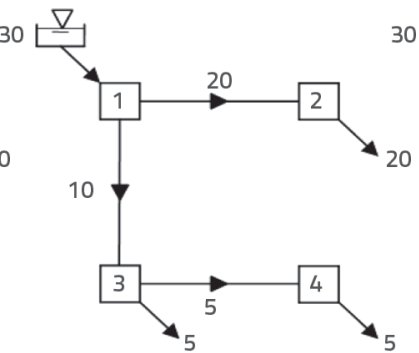

(2)

$S_{2}=0,8675$

$\mathrm{S}_{2}^{\prime}=0,7436$

$S_{2}^{\prime \prime}=0,7121$

$S_{1}^{\prime}=0,3470$
$S^{\prime \prime}=0,2304$

a)

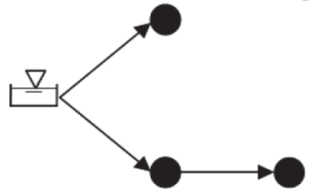

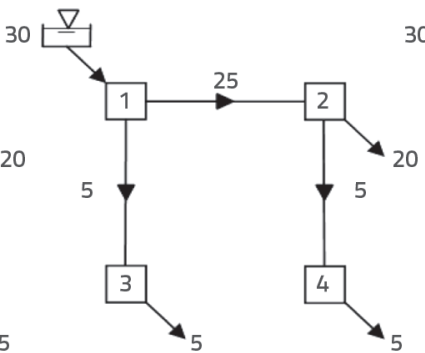

(3)

$S_{3}=0,8675$

$\mathrm{S}_{3}=0,7436$

$\mathrm{S}_{3}=0,3727$

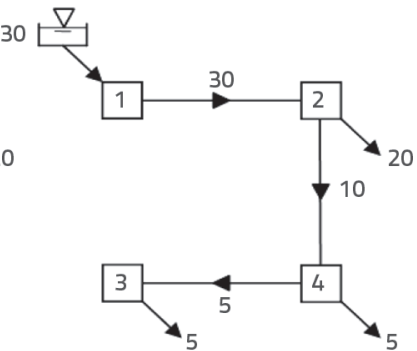

(4)

$\mathrm{S}_{4}=0,8675$

$\mathrm{S}_{4}^{\prime}=0,5784$

$\mathrm{S}_{3}^{\prime \prime}=0,3063$

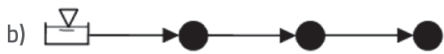

Figure 10. Four branching-tree networks related to sample loop network shown in Figure 9, and their connectivity state graphs based on Hosseini and Ememjomeh [26]: a) Connectivity state graph for networks 2 and 3; b) Connectivity state graph for networks 1 and 4

It can be seen in Figure 10 that Tanyimboh-\&-Templeman's formula gives the same entropy values for all four branching-tree networks, which is not what one could expect. In fact, looking at the amount of flow rates and the connectivity graphs of the four branching-tree networks, shown in Figure 10, one would expect entropy values of the four networks in the following descending order: $2,3,4$, and 1 . Thus neither the Tanyimboh\&-Templeman's formula nor the Hosseini and Ememjomeh modified formula leads to the expected results, while logical results are obtained using the modification proposed in this study. In order to see the effect of failure probabilities of the network links in entropy value, its values has been calculated using the proposed modified formulae and the results are shown in Figures 11 to 13.

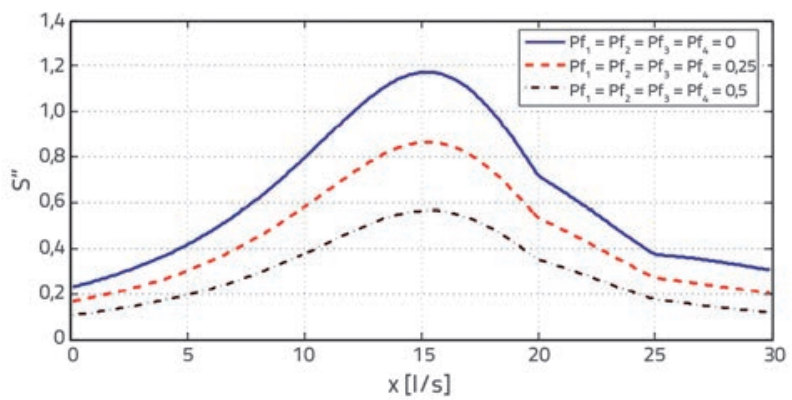

Figure 11. Entropy variations of sample loop network versus flow rate of link 1 based on proposed entropy function, in case of similar failure probability for all links

Figure 11 compares three cases of zero, 0.25 and 0.50 failure probabilities, assumed to be the same for all links of the network. The general decreasing effect of increase in the failure probability on the entropy value is easily observed in the figure. This figure also shows that, in all states, maximum entropy of the network is obtained when $x=15 \mathrm{~L} / \mathrm{s}$, which means that division of the whole supply of the network is divided into two equal amounts between its two main branches connected to the supply node, which is quite logical.

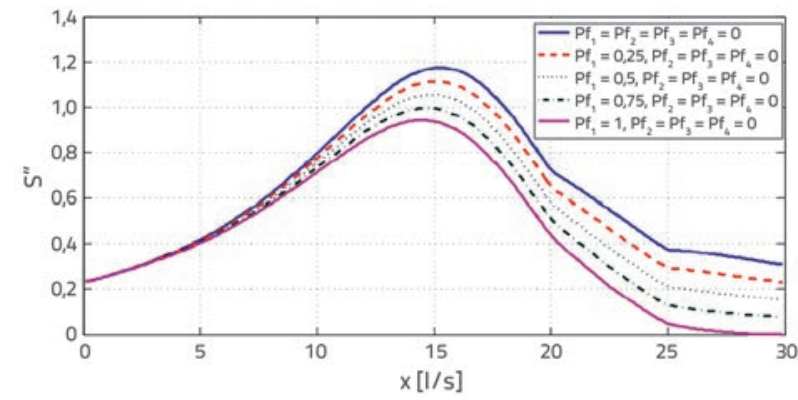

Figure 12. Entropy variations of sample loop network versus flow rate of link 1 based on proposed entropy function, in case of various failure probabilities in link 1 only

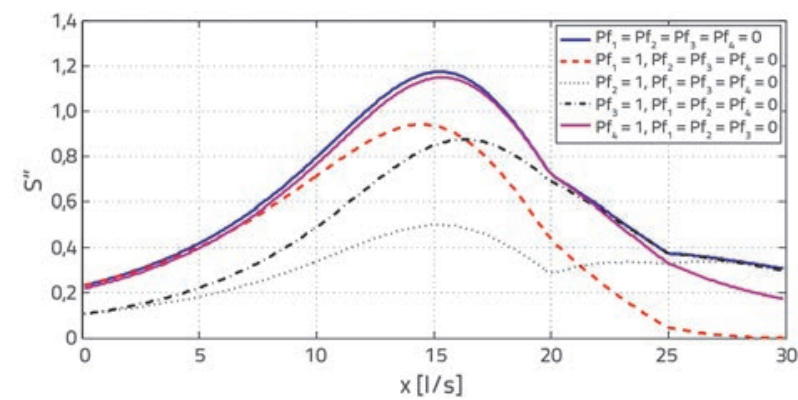

Figure 13. Entropy variations of sample loop network versus flow rate of link 1 based on proposed entropy function, in case of complete failure of each individual link

This is why Tanyimboh-\&-Templeman's formula gives an amount of $10 \mathrm{~L} / \mathrm{s}$ as the amount resulting in maximum entropy. It is worth mentioning that the start and end points as well as the slope 
change points in the presented graphs in Figure 11 correspond to the branching-tree states of the network, which are related to the $x$ values of $0,20,25$ and $30 \mathrm{~L} / \mathrm{s}$, respectively. Other values of $x$ result in the loop state in the network. It can be seen in all graphs, shown in Figure 11, that entropy values for the case of $x$ $=20 \mathrm{~L} / \mathrm{s}$, which corresponds to a branching-tree state, are larger than the entropy values for cases of $x>20 \mathrm{~L} / \mathrm{s}$ as well as $x<8 \mathrm{~L} / \mathrm{s}$, which correspond to the loop state of the network. This means that some branching-tree networks can be more reliable than loop networks.

Figure12 shows a state in which only link 1 has various failure probabilities. As expected, by an increase in the failure probability of link 1, the entropy value decreases in all cases, while the general trend of the graphs does not change.

An interesting issue that is usually a cause of concern for authorities of a network is the network sensitivity to the elimination of its link. In other words, which link is the most important link of the network? Figure 13, which shows the states in which the failure probability of all links, except one of them, is zero, can be used to respond to this question. As it is observed in Figure 13, the network sensitivity to elimination of its links differs for various flow rates of link 1. More generally, it can be said that network sensitivity to elimination of each link is dependent on the pattern of flow distribution in the network. For example, for $0 \leq x \leq 20$, in which the flow distribution pattern is the same as in Figure 8.a, the network has more sensitivity to elimination of link 2, while for $20 \leq x \leq 25$, the flow distribution pattern is same as in Figure 8.b, where the network is more sensitive to elimination of either link 2 or link 1; actually, for some $x$ values in this range, link 2 is the most important one and, for some other $x$ values, link 1 is the most important one. Also, for the case of $25 \leq x \leq 30$, the flow distribution pattern is the same as in Figure 8.c, where the network is more sensitive to elimination of link 1.

The aforementioned sensitivity can better be shown by investigating cases in which $x$ takes some specific values. For example, in case of $x=10$, the case shown in Figure 2.a, it is clear that link 2 is the most important one while links 3, 1, and 4 are less important, respectively, which is due to the fact that with elimination of link 2, the network entropy value is lower than the network entropy value when links 3, 1, and 4 are eliminated. As a result, link 2 is the most important link in the network. With the elimination of link 3, the network entropy value is higher than the case in which link 2 is eliminated, and is lower than the case in which links 1 and 4 are eliminated. Therefore, link 3 is less important than link 2 and more important than links 1 and 4 . This result is in agreement with the expectation raised from the flow rates shown in Figure 2a. As another example, in case of $x=$ 22.5 , links 1 and 2 are respectively the most important and the second important links of the network, and links 3 and 4 are of equal importance. This result is in agreement with the flow rates in Figure 2.b. As the last example, in case of $x=27.5$, link 1 is the most important link, link 4 is the second most important one, and links 2 and 3 are of the same significance as the third most important links. This result is in agreement with the flow rates shown in Figure 2.c.

\section{The case study}

A part of water distribution network of Kobe city, which has been used in several case studies for calculation of redundancy indices by Hoshiya et al. [15] and Javanbarg [8, 12, 27, 28], was considered in order to evaluate efficiency of the proposed entropy function. Kobe water supply department has constructed a new transmission system through the downtown area (Figure 14) which is a backup facility for the existing transmission pipelines and can supply water to the existing links and demand nodes directly. Moreover, it could play an important role as a water reservoir for the aftermath of probable earthquakes.

Models of the present water distribution network in HigashiNada ward of Kobe city and the strengthened network, proposed and studied by Javanbarg and Takada [12, 27], are shown in Figure 15. Specifications and geometrical and hydraulic features of links and nodes of the present and strengthened networks are given in Table 3.

Characteristics of links 1 to 20 and the water flow demand for nodes 2 to 15 are the same in both networks. In Table 3 DIP and CIP represent ductile iron pipe and cast iron pipe, respectively. In calculations, roughness coefficients of these two kinds of pipes are assumed to be 140 and 130, respectively. In the strengthened network model (Figure 15.b), there are two new supply nodes, namely, $\mathrm{S}_{1}$ and $\mathrm{S}_{2}$ as imaginary sources from the new transmission pipeline which can supply water through

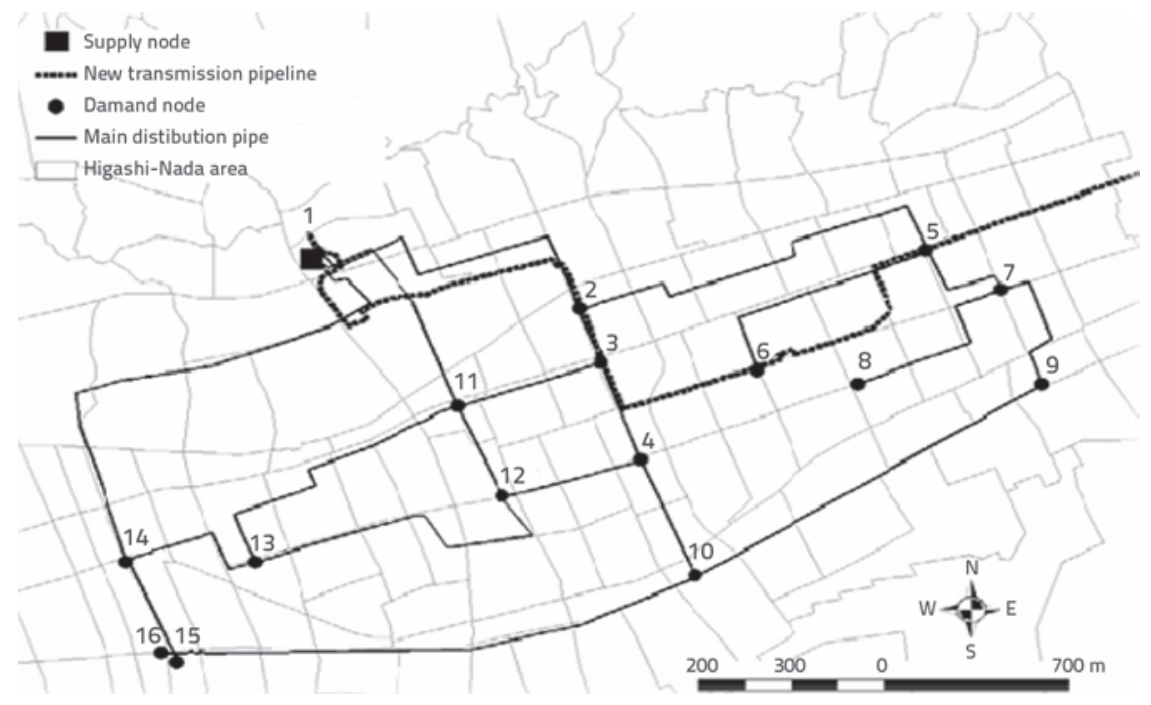

Figure 14. Main water distribution pipeline in Higashi-Nada ward of Kobe city [12] 

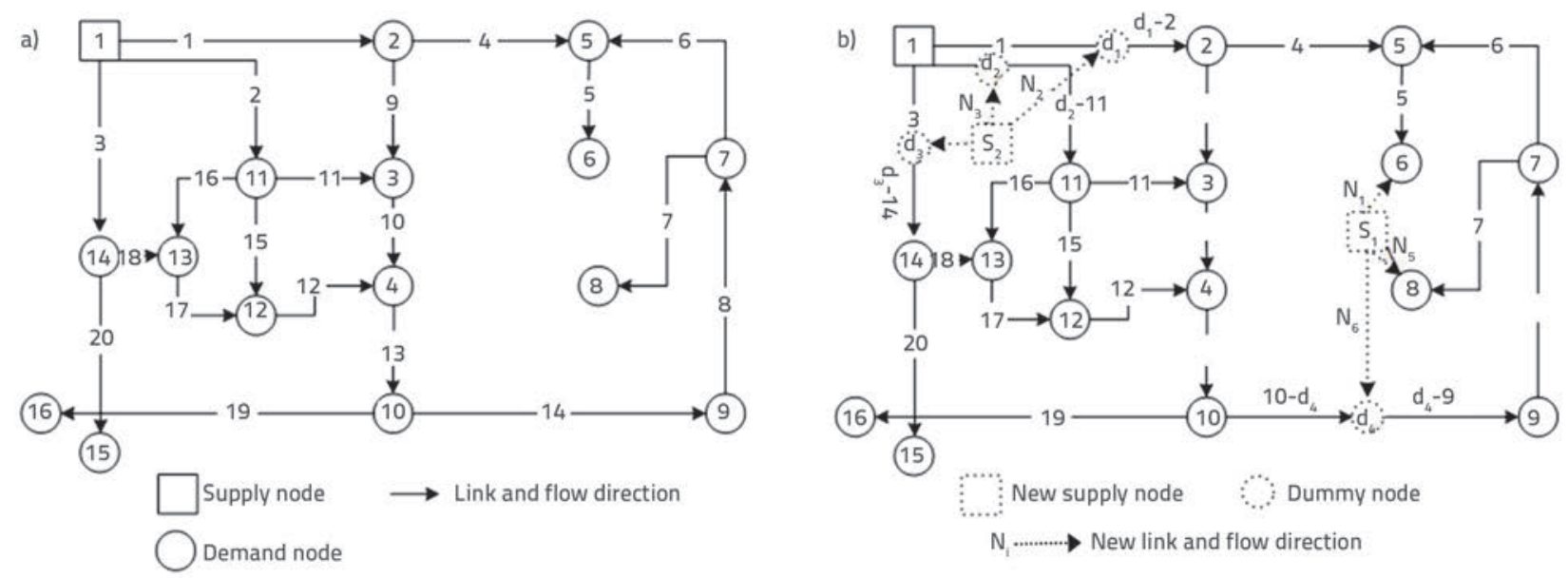

Figure 15. Models of present network of: a) Higashi-Nada ward of Kobe city; b) strengthened network [12]

Table 3. Characteristics of links and nodes of present and strengthened network of Higashi-Nada ward of Kobe city [12]

\begin{tabular}{|c|c|c|c|c|c|c|c|}
\hline Link (pipe) No & $\begin{array}{c}\text { Length } \\
{[\mathrm{km}]}\end{array}$ & Pipe material & Diameter [mm] & Pf & $\begin{array}{c}\text { Flow rate } \\
{\left[\mathrm{m}^{3} / \text { day }\right]}\end{array}$ & Node No. & $\begin{array}{c}\text { Water flow demand } \\
{\left[\mathrm{m}^{3} / \text { day }\right]}\end{array}$ \\
\hline 1 & 1.183 & DIP & 900 & 0.284 & 26176.5 & 2 & 2237.00 \\
\hline 2 & 0.818 & DIP & 700 & 0.208 & 7873.9 & 3 & 1678.00 \\
\hline 3 & 2.193 & DIP & 900 & 0.347 & 15728.4 & 4 & 3356.00 \\
\hline 4 & 1.472 & DIP & 300 & 0.572 & 6068.5 & 5 & 4475.00 \\
\hline 5 & 0.973 & DIP & 300 & 0.421 & 2797.0 & 6 & 2797.00 \\
\hline 6 & 0.474 & DIP & 300 & 0.212 & 1203.4 & 7 & 2237.00 \\
\hline 7 & 0.726 & DIP & 500 & 0.404 & 3356.0 & 8 & 3356.00 \\
\hline 8 & 0.673 & DIP & 500 & 0.271 & 6796.4 & 9 & 3356.00 \\
\hline 9 & 0.248 & DIP & 900 & 0.085 & 17871.0 & 10 & 5593.00 \\
\hline 10 & 0.440 & DIP & 900 & 0.151 & 18088.4 & 11 & 2237.00 \\
\hline 11 & 0.616 & DIP & 300 & 0.175 & 1895.4 & 12 & 5593.00 \\
\hline 12 & 0.522 & DIP & 700 & 0.162 & 3530.0 & 13 & 3915.00 \\
\hline 13 & 0.562 & DIP & 500 & 0.167 & 18262.4 & 14 & 3915.00 \\
\hline 14 & 1.559 & DIP & 400 & 0.393 & 10152.4 & 15 & 2517.00 \\
\hline 15 & 0.411 & DIP & 300 & 0.115 & 2576.0 & 16 & 2517.00 \\
\hline 16 & 1.230 & DIP & 300 & 0.309 & 1165.5 & d1 & 0.00 \\
\hline 17 & 1.409 & DIP & 700 & 0.342 & 6546.9 & d2 & 0.00 \\
\hline 18 & 0.524 & DIP & 700 & 0.149 & 9296.4 & d3 & 0.00 \\
\hline 19 & 2.033 & CIP & 500 & 0.894 & 2517.0 & d4 & 0.00 \\
\hline 20 & 0.437 & DIP & 900 & 0.149 & 2517.0 & & \\
\hline N1 & 0.100 & * & 300 & 0.0 & 2797.0 & & \\
\hline N2 & 0.780 & * & 500 & 0.0 & 26176.5 & & \\
\hline N3 & 0.200 & * & 700 & 0.0 & 7873.9 & & \\
\hline N4 & 0.100 & * & 500 & 0.0 & 15728.4 & & \\
\hline N5 & 0.570 & * & 500 & 0.0 & 3356.0 & & \\
\hline N6 & 0.720 & * & 500 & 0.0 & 10152.4 & & \\
\hline
\end{tabular}


$d_{1}$ to $d_{4}$ dummy nodes by $N_{1}$ to $N_{6}$ new pipes. These new links and dummy nodes represent a simplified version of the new transmission pipeline whose failure probabilities are assumed to be zero because of its earthquake-proof construction. In case of a disaster, pipe numbers $5,1,2,3,7$, and 14 can be substituted by $N_{1}$ to $N_{6}$ pipes, respectively. Thus, the flow rate in pipes $\mathrm{N}_{1}$ to $\mathrm{N}_{6}$ can be considered similar to that in pipes $5,1,2$, 3,7 , and 14 , respectively $[12,27]$.

Based on their proposed redundancy index, Hoshiya et al. [15] calculated redundancy index of the present network and the strengthened network, and this index amounts to 0.563 and 0.598 , respectively. They concluded that the network performance had improved by $6.2 \%$. However, Javanbarg et al. [12] concluded that using their own entropy-based redundancy measure the seismic redundancy of the strengthened network had increased by $30 \%$.

Based on the entropy function proposed in this study, the entropy values for the present and strengthened networks amount to 0.1388 and 0.1614 , respectively. Hence, if the entropy value is considered as a reliability criterion, it can be concluded that the proposed entropy function represents a $16.3 \%$ performance improvement in the strengthened network. Evidently, the entropy function proposed in this study could be used to evaluate network performance improvement with greater reliability as it takes into account both design and hydraulic parameters.

\section{Conclusion}

Based on numerical calculations performed in this study for sample networks as well as for a part of Kobe city water distribution network, the following conclusions can be made. Examining the entropy function proposed by Tanyimboh and Templeman and modifications of this function as made by other researchers, the following deficiencies can be observed:

- in the function proposed by Tanyimboh and Templeman, the entropy amount is calculated using the flow rate of links, i. e. only the hydraulic parameters of the network. Furthermore, design parameters such as the length, diameter, and the material of the links are neglected in their calculations

- in the original Tanyimboh-\&-Templeman's entropy function, the difference between various flow directions of the network and the connectivity order of demand nodes to the supply node are not contributed and, even in its modified version proposed by Hosseini and Emamjomeh, it cannot realistically represent these features

- Hosseini and Emamjomeh's modified version of Tanyimboh\&-Templeman's entropy function cannot consistently measure network improvement after repairs or changes.

Replacing the previous ratio for demand nodes by a new weighting factor as the total outflow at each node to the total dissipated power in the network, as proposed in this study, the design parameters of the network are taken into account in entropy calculations, and the aforementioned deficiencies of Tanyimboh-\&-Templeman's function, as well as its modified version, proposed by Hosseini and Emamjomeh, can be resolved. Failure probabilities of the network's links, defined by a penalty function in the Hosseini and Emamjomeh's study, were applied to the existing entropy function of the network in a more suitable way. Furthermore, to consider the effect of link's importance in different states of flow direction in the network, a new weighing factor was defined as the flow rate in the link to the total flow rate of network multiplied by the probability of a link being chosen by a water molecule. This resulted in a more logical calculation of the network's reliability.

By using the proposed modified entropy function, making decision on seismic upgrading or replacement of the network's links can not only be done more reliably, but also a more optimal plan can be chosen for designing new networks.

Finally, it should be mentioned that in this study the performance of network links is based on either complete service or complete failure and, therefore, the cases in which failure involves a wide range of damage, from slight leakage to full breakage, are not considered. Further research is required to address such cases.

\section{REFERENCES}

[1] Wagner, J.M., Shamir, U., Marks, D.H.: Water distribution reliability: simulation methods, ASCE J. Water Resour. Plan. Manag., 114 (1988) 3, pp. 276-294.

[2] Fujiwara, O., De Silva, A.U.: Algorithm for reliability-based optimal design of water networks, ASCE J. Environ.Eng., 116 (1990) 3, pp. 575-587.

[3] Khomsi, D., Walters, G.A., Thorley, A.R.D., Ouazar, D.: Reliability tester for water-distribution networks, ASCE J. Comput. Civil Eng., 10 (1996) 1, pp. 10-19.

[4] Gargano, R., Pianese, D.: Reliability as a tool for hydraulic network planning, ASCE J.Hydraul. Eng., 126 (2000) 5, pp. 354-364.

[5] Tanyimboh, T.T., Tabesh, M., Burrows, R.: Appraisal of source head methods for calculating reliability of water distribution networks, ASCE J. Water Resour. Plan. Manag., 127 (2001) 4, pp. 206-213.

[6] Shinstine, D.S., Ahmed, I., Lansey, K.E.: Reliability/availability analysis of municipal water distribution networks: case studies, ASCE J. Water Resour. Plan. Manag., 128 (2002) 2, pp. 140-151.

[7] Mays, L. W., ed.: Reliability analysis of water distribution systems, ASCE, New York, 1989.

[8] Javanbarg, M.B, Scawthorn, C, Kiyono, J., Ono, Y.: Safety, Reliability analysis of infrastructure and lifeline networks using OBDD, Safety, Taylor \& Francis, Reliability and Risk of Structures, Infrastructures and Engineering Systems, 2010.

[9] Awumah, K., Goulter, I., Bhatt, S.K.: Assessment of Reliability in Water Distribution Networks Using Entropy-Based Measures, Stochastic Hydrology and Hydraulics, 4 (1990), pp. 309-320, https://doi.org/10.1007/BF01544084 
[10] Tanyimboh, T.T., Templeman, A.B.: A Quantified Assessment of the Relationship Between the Reliability and Entropy of Water Distribution Systems, Engineering Optimization, 33 (2000), pp. 179-199, https://doi.org/10.1080/03052150008940916

[11] Awumah, K., Goulter, I., Bhatt, S.K.: Entropy Based Redundancy Measures in Water Distribution Network Design, ASCE, Journal of Hydraulic Engineering, 117 (1991), pp. 595-614, https://doi. org/10.1061/(ASCE)0733-9429(1991)117:5(595)

[12] Javanbarg, M.B., Takada, S.: Entropy-based redundancy measures for water distribution network under seismic risk, Memoirs of Construction Engineering Research Institute, 48 (2006), pp. 119132.

[13] Kalungi, P., Tanyimboh, T.T.: Redundancy model for water distribution system, Reliability Engineering and System Safety, 82 (2003), pp. 275-286, https://doi.org/10.1016/S09518320(03)00168-6

[14] Hoshiya, M., Yamamoto, K.: Redundancy index of lifeline systems. ASCE J. Engrg. Mech., 128 (2002) 9, pp. 961-968.

[15] Hoshiya, M., Yamamoto, K., Ohno, H.: Redundancy index of lifeline for mitigation measures against seismic risk, Probabilistic Engineering Mechanics, 19 (2004), pp. 205-210, https://doi. org/10.1016/j.probengmech.2004.02.003

[16] Shannon, C.: A Mathematical Theory of Communication, The Bell System Technical Journal, 27 (1948), pp. 379-423, https://doi. org/10.1002/j.1538-7305.1948.tb01338.x

[17] Khinchin, A.l.: The entropy concept in probability theory, Uspekhi Mathematicheskikh Nauk, 8 (3), 2-30. Translation in Khinchin, A. I. (1957) Mathematical Foundations of Information Theory. Dover, New York, pp. 1-28, 1958.

[18] Tanyimboh, T., Templeman, A.: Calculating Maximum Entropy Flows in Networks, The Journal of the Operational Research Society, 44 (1993) A, pp. 383-393.

[19] Tanyimboh, T., Templeman, A.B.: Maximum Entropy Flows For SingleSource Networks, Engineering Optimization, 22 (1993) B, pp. 49-63.
[20] Walters, G.A.: Discussion on: Maximum Entropy Flows in Single Source Networks, Engineering Optimization, 25 (1995), pp. 155-163, https://doi.org/10.1080/03052159508941260

[21] Yassin-Kassab, A., Templeman, A.B., Tanyimboh, T.T.: Calculating Maximum Entropy Flows In Multi-Source, Multi-Demand Networks, Engineering Optimization, 31 (1999), pp. 695-729, https:/doi. org/10.1080/03052159908941393

[22] Tanyimboh, T., Templeman, A.B.: A Quantified Assessment of the Relationship between the Reliability and Entropy of Water Distribution Systems, Engineering Optimization, 33 (2000), pp. 179199, https://doi.org/10.1080/03052150008940916

[23] Ang, W.K., Jowitt, P.: Some Observations on Energy Loss and Network Entropy in Water Distribution Networks, Engineering Optimization, 35 (2003), pp. 375-389, https://doi. org/10.1080/0305215031000154668

[24] Ang, W.K., Jowitt, P.: Some New Insights on Informational Entropy for Water Distribution Networks, Engineering Optimization, 37 (2005) A, pp. 277-289.

[25] Ang, W.K., Jowitt, P.: Path Entropy Method for Multiple-Source Water Distribution Networks, Engineering Optimization, 37 (2005) B, pp. 705-715.

[26] Hosseini, M., Emamjomeh, H.: Entropy-Based Serviceability Assessment of Water Distribution Networks Subjected to Natural and Man-Made Hazards, International Journal of Engineering, 27 (2014), pp. 675-688.

[27] Javanbarg, M.B., Takada, S.: Redundancy model for water supply systems under earthquake environments, The $5^{\text {th }}$ International Conf. on Seismology and Earthquake Engineering, Tehran, Iran, 2007.

[28] Javanbarg, M.B., Scawthorn, C., Kiyono, J., Ono, Y.: Minimal Path Sets Seismic Reliability Evaluation of Lifeline Networks with Link and Node Failures, TCLEE2009, ASCE, pp. 1108-1119, 2009. 